\title{
Elements of Inclusion: Findings from the Field
}

\author{
Christopher McMaster \\ University of Canterbury
}

\begin{abstract}
The Ministry of Education has set the target of 100\% of New Zealand schools to be 'mostly' inclusive by 2014. But what are the essential elements of inclusion? This paper explores essential core elements that allow inclusion to flourish. Based on an extensive time in the field as part of a year-long doctoral research project, these elements are: relationships; shared experiences; advocacy, and a sense of identity. Strengthened and welded together through transparency, inclusive cultures and more inclusive practices have been seen to develop and grow.
\end{abstract}

\section{Practice Paper}

Key Words: Advocacy, change, inclusion, transparency

\section{INTRODUCTION}

Inclusion has been likened to a process (Ainscow, 2005; Allan, 2008; Carrington, 1999). Rather than a set destination, considering inclusion as a process has required from educators a continuous effort of reflection and improvement. The Ministry of Education is determined to announce the arrival of the New Zealand education system at some sort of inclusive destination (Ministry of Education, 2012). The Education Review Office's (ERO) most recent report, Including Students with High Needs: Primary Schools (Education Review Office, 2013) announces that we are 77 percent there. However, when inclusion is considered as an issue of social justice rather than a measurable goal, it assumes a wider meaning (Ballard, 2004). Inclusion, when viewed as an issue of values and beliefs, becomes focused on any member of the school or community who face barriers to full and meaningful participation.

I have written previously about examples of successful inclusion found in the literature (McMaster, 2012). While there is no set recipe for achieving a 'world class inclusive education system', each example offered ingredients that schools could use to create their own 'flavour' of inclusion.
The literature revealed that these were:

- Developing a shared vision and common definition (or language) of inclusion

- A process of learning reflecting best-evidence synthesis for professional learning and development

- Change that takes place on the cultural level.

Kugelmass (2006) has identified aspects of culture demonstrated in schools striving to become more inclusive:

- an uncompromising commitment and belief in inclusion

- differences among students and staff perceived as a resource

- teaming and a collaborative interaction style among staff and children

- willingness of staff to struggle to sustain practice

- inclusion understood as a social/political issue, and

- a commitment to inclusive ideals communicated across the school and into the community (p. 286).

This paper will look within those ingredients and cultural aspects and discuss essential core elements that enable inclusive change. These elements are relationships, advocacy, a sense of identity, shared experiences, and transparency. Each of these elements work to strengthen the effort to develop inclusion in schools and communities. These elements fuel inclusive change in an everenlarging spiral - the more they are developed, the stronger the foundations (or ingredients) for inclusive change to emerge, and the more pronounced these core elements become. Woven throughout these elements is the notion of transparency, being able to see barriers as well as through them. Transparency involves the ability to see how values and beliefs are demonstrated within a school or community. This improved vision allows community members to see who is included or who is excluded, to look outward at how values are practiced, as well as inward to where values are formed. 
The research findings discussed in this paper reflect the importance of school culture as central in inclusive development. This paper demonstrates the inter-relation between inclusion and school culture (Booth \& Ainscow, 2011; Slee, 2011; Zollers, Ramanathan \& Yu, 1999). However, culture is not a fixed entity. When action is grounded in reflection, and reflection leads to action, there is praxis. Change becomes possible in a directed manner when underlying values and assumptions are examined. Carrington, Deppeler and Moss (2010) argue that schools need to reflect on their values and beliefs in order to develop inclusive cultures. Culture, Carrington (1999) points out, is constructed by the beliefs and attitudes of people in a community. "Reflection on current beliefs and practices is necessary", Carrington concludes, to develop inclusive education (p. 262).

\section{The Social Model of Disability}

Language, like culture, has a certain fluidity of interpretation. Words such as 'disability' and 'inclusion' have been difficult to define. The definition of disability in this paper reflects a 'social model' (Oliver, 1996; Oliver \& Barnes, 2012). A social model of disability moves the focus away from the individual and recognises the oppressive social or political structures that exclude or marginalise that individual (Neilson, 2005; Oliver, 1990). Oliver (1990) drew a distinction between impairment and disability. An impairment may be a physical condition or functional limitation, however, a disability is the social exclusion created by the way a society responds to individuals with impairments (Joseph, 2007). Some disability researchers today prefer the term 'social interpretation(s)' to more fully describe the complex societal roles in disablement but there is general agreement that disability is a social construct. A common feature among disability research is the rejection of a medical model of disability (Connor, Gabel, Gallagher \& Morton, 2008). A medical model of disability individualises and pathologises disability (Neilson, 2005). The underlying assumption within this 'medical' paradigm is that the deficit is located within individual students. In this model a child receives a diagnosis of his or her impairment, which can then be used to group individuals together for instructional purposes (Mitchell, 2010). When the focus of disability or impairment is within the individual, the environment or culture does not need to be restructured. Instead, the individual becomes a subject to be 'integrated' into a 'mainstream' or 'regular' educational setting.

In a social model of disability the focus of attention shifts from the individual to the barriers that the individual faces in their community, workplace or school. Creating an inclusive education system, then, would necessitate the identification and removal of barriers. This activity, carried out at the level of school culture, would allow for the cultural transformation that Kugelmass (2006) sees as necessary for inclusive change to be sustained. This notion of 'cultural transformation' implies an agency in school community members (teachers, students, parents) to redefine terms such as 'inclusion' and 'mainstream' to reflect the shared values of the community. During my research at the subject school a process of negotiation and re-negotiation was continually taking place at a conscious, as well as subconscious level, as staff explored how these terms were reflected in school practice. The word 'mainstream', for example, is used with quotation marks in this paper as the notion of what or who were 'mainstream', and indeed, even the appropriateness of that term, was questioned and explored. The ability of the school community to co-create meaning through experience and reflection highlights the potentiality of developing inclusive schools. This is the conscious effort of which Kugelmass (2006) writes, coupled with a supportive and collaborative atmosphere deliberately created to foster an exploration of deeply-held values and beliefs.

\section{The Context of this Research}

This paper represents some initial findings of my doctoral research. I have been looking at whole-school inclusive change in an Aotearoa/New Zealand high school setting, using the Index for Inclusion (Booth \& Ainscow, 2011) as a tool for reflection and review in a year-long critical ethnographic qualitative project. The discussion offered below is based on extensive field notes (Biklen \& Bogdan, 2007) and interviews of both an informal and formal nature (Kvale, 2008). My chosen methodology has given me a unique and in-depth view of both the school culture and the process of change. For the length of one academic year I was embedded in the subject school as critical ethnographer (Madison, 2005; O'Reilly, 2008) and facilitator for the Index process. While researching for my doctoral thesis I was also an active agent for change, working with the staff team in developing inclusion within their school. In order to ensure anonymity I have used no names in this paper. The school is referred to simply as 'the subject school', and simple titles or descriptors are utilised such as 'the unit', 'learning support area', 'principal', etc. This is also done in the belief that the findings presented below do not merely reflect the experiences of one school, but may be generalised to the wider New Zealand context. As this research has been conducted under the auspices of an accredited university, ethical 
approval has been sought and granted by the ethics committee of that institution, and the Code of Ethics followed in all research practice.

\section{ELEMENTS OF INCLUSION}

Five essential elements have emerged in looking at inclusion: relationships, shared experiences, advocacy, a sense of identity, and transparency. Although treated separately in this paper they all intertwine and work together to energise the features Kugelmass (2006) identified as related to inclusive education. Each core element makes up a vital part of school members' efforts to create sustainable inclusive change.

\section{Relationships}

The most obvious of the elements listed above is, perhaps, relationships - inclusion boiled down to the most basic of questions: "Do I know you?" Knowing an individual brings that person to our consciousness, making them, in an important way, part of us. We know family and friends and colleagues. Through knowing them we form a bond, and through this bond we demonstrate respect and show care. We miss those who we know and we notice their absence at daily or key events. When entering a crowded room, such as a school assembly, a quick look around the group will tell us if those we know are present or absent. Through developing a relationship with the students of the unit and learning support classes in the subject school I was easily able to spot their non-participation during school presentations. "__ would really enjoy this!" " sure would get a lot out of this motivational speaker!" Because those students were known to me I was able to think those thoughts (thoughts that now include them). Had I not known those students I would have enjoyed the events with those around me, unfettered by a sense of loss or guilt or anger that my friends were not invited.

Teachers care greatly for their students. A crucial question to explore is: "Who are their students?" Or, whom do they consider to be their students? The more a teacher widens their circle of relationships with students the more their sense of 'ownership' of students increases. If a small group of students are not known to them then they may feel no responsibility towards them. There is no emotional or even professional attachment as they have no, or very limited, interaction with them. It is very possible that the longer a teacher has taught at a school the more students they become familiar with. A teacher in the 'mainstream' will have a greater opportunity to develop relationships with (primarily) 'mainstream' students. How are these relationships defined? How do the teachers identify the students as well as identify or relate to them? How well do they know a student if the interaction is limited to specific timelimited periods during the week? This, of course, is difficult to measure but interactions outside of these periods can be an indicator. An important factor in this interaction is the amount of time or opportunity that an individual student has to participate in the general 'mainstream' life of the school.

A perception with several teachers in the subject school was that inclusion involved removing special settings and 'including' all students in 'mainstream' classes. A Resource Teacher: Learning and Behaviour (RTLB) working with the school spoke of teacher frustration elsewhere at having such a diverse ability range in their classes, of facing real exhaustion at trying to meet all student needs as professionally as possible. "Real exhaustion," he reiterated. This is confusing inclusion with service provision - how additional needs are met. An occupational therapist (OT) I interviewed told of one girl at another school who is 'included' in a class with her peers for two hours each day. "All she does is wander around the class the whole time - that isn't inclusion." I had to agree. That is an example of service provision, how additional needs are, or not, met. Viewing inclusion as an issue of values and attitudes, the primary focus becomes how the individual student is valued in his or her local school, how teachers and peers reflect their appreciation and respect for that individual through their relationships with them.

In that $\mathrm{OT}^{\prime}$ s experience, schools with a unit provided more opportunity for inclusion. The provision of services was met through the additional classroom and a quality participation in school life was made possible. The unit can enable all students, regardless of need, to attend the local school. This presence is guaranteed through a certain model of service provision. However, presence is not enough. Without increasing participation in the general life of the school it is not even 'integration', and definitely not 'mainstreaming', to borrow a very old term. An essential element in making any type of inclusion successful is the ability of teachers and students to weave relationships. Through relationships we identify with and value the other, we notice their absence or exclusion, and we look for ways to include them. We widen our circle to include them.

\section{Advocacy}

Advocacy, whether self-advocacy or that provided by another, is another essential element that fertilises inclusion. There is a student at the school who utilises a prosthetic leg, and as such, fits many definitions of 'disabled'. However, this student can advocate for themself and has ensured that they receive no special 
treatment, no separate placement, and no additional supports except those requested specifically by them. Only by watching the student walking freely around campus is any type of limp detectable. The student reminded me of my own daughter who very strongly advocated that she be removed from the English equivalent of Ongoing Resourcing Scheme. She did not consider herself to be 'disabled' or 'special'. Once she was removed from that funding scheme and received no additional supports she became just another student and experienced 'inclusion'. That this self-advocacy was respected by the teaching staff contributed to the self-confidence and empowerment of the student and is consistent with United Nations Convention on the Rights of the Child (United Nations, 1989; 2006) and the United Nations Convention on the Rights of Persons with Disabilities (United Nations, 1989; 2006).

A student without a perceived disability is only known by her name, not her class, such as a 'learning support' student or 'one of [unit teacher's]'. The latter description was overheard when a young lad with autism walked into the administration block. A senior staff member tried to explain his presence to a bemused colleague. "He is one of [unit teacher's]," had the ring of explanation. I used the opportunity to say hello to the boy and extend a hand which he promptly shook. When he had walked past, a teacher asked what his green flag was for, and I was able to explain that after watching the stock cars on a previous evening, waving the flag and starting a race is one of his favourite activities. On that occasion I was able to use the experience to normalise a relationship and advocate quietly for the student.

Lack of advocacy not only results in non-participation but the lack of voice. Without an advocate to push for inclusion, and lacking the skills to effectively speak for oneself, a situation of exclusion more readily emerges. For example, one way that this can occur is if there is a lack of response to students who experience communication challenges. This can result in exclusion from the curriculum and from social relationships. Impairments can be turned into disabilities if no effective means of communication are provided. Similarly, if there is no-one to advocate for the student, to notice the absence of students at school events, there is no person to query that absence or to encourage, even demand, more meaningful participation. Advocacy in a school where the culture is one of ownership by all the teachers can be seen as a vigilance (Cologon, 2013). This is what Kugelmass (2006) refers to as an uncompromising commitment and belief in inclusion. In such a case advocacy is not limited to one teacher's aide or teacher, but a shared responsibility.

\section{Sense of Identity}

In departments or units that have a strong sense of identity there is a linking of advocacy and experience. The learning support area of the school, comprising four classrooms, has been working deliberately to foster a sense of identity and shared focus. The four teachers use their weekly meeting (held during Friday form period in all departments) to plan forward as well as bond as a team. The weekly assembly held in the library for all the students of the four classes provides an opportunity to share success, offer praise and build esteem. The parent consultation evening was held this year in the learning support area itself (rather than in the crowded hall where teachers sit at individual tables) and parental participation increased markedly. The Head of Department is consciously trying to ensure the full participation of the learning support students in the curriculum, advocates strongly for those students, with varying degrees of success, to have access to subjects such as science, and is creatively looking at how to incorporate her department more fully and reciprocally into the life of the school.

The subject school in which my research took place also maintains a unit for students with high and complex needs. Separate units can make a powerful physical statement about who is ' $\mathrm{in}^{\prime}$ and who is 'out' in any community (Slee, 2011). Separate or special locations for specific students can imply that those students do not fit in with what is considered 'normal' or 'regular'. The presence of a special needs unit, however, can mean that no impairment can prevent attendance at a mainstream school. There is great potential in the special needs unit in facilitating inclusion. How the special needs unit is utilised is where inclusion or segregation can happen (McMaster, 2014). Having worked previously with units possessing a strong sense of identity I have seen what can be achieved when it is fostered. A unit in a high school in another area, for example, recreated itself, name and all, in an effort to integrate more fully into the life of school. The teacher was a tireless advocate, utilising the resources and relationships of the school as well as outside sources such as Crippled Children's Society, RTLB, and the Ministry of Education, Special Education. Student voice was made central to practice and planning, and outside advocacy was accessed to ensure student wishes and goals were met. Each student had an individualised schedule to meet their needs and desires, and they and their families/whanau played a significant role in creating those schedules. Here is an example of the inter-relatedness of this sense of identity with advocacy, relationships and shared experiences, and a reflection of the six aspects of culture identified by Kugelmass (2006) as necessary 
for sustaining inclusive cultures in schools. Where the sense of identity is strong there is more confidence in advocacy, there are more opportunities to share in experience, and more relationships are formed. When it is lacking, isolation and exclusion become the norm.

\section{Shared Experiences}

Were the participation of all students normalised then their presence would be expected. Inclusion, in other words, would be the norm or the commonplace. The school community sharing in experiences becomes not only what is expected; it is what the community is used to. Shared experiences, doing and celebrating together, creates a familiarity in which those unknown become known. Shared experiences, such as whole school sports day, a water sports day, an art exhibition featuring a wide variety of student art, creates a space in which community members are able to be with each other in non-threatening or non-judgemental circumstances. Every school week or term provides such occasions, and every school term affords enough time to plan and create such celebrations. All that is required is imagination and facilitation. The more experiences are shared, the more familiar faces become, the more known community members become.

Never underestimate the power of unfamiliarity. Unfamiliarity is the cause of awkwardness. Standing in the playground and speaking with a staff member on a sunny autumn afternoon, a student from the unit came up to us. He was in good spirits and we began chatting. It turned out the staff member was related in a second cousin or distant aunty way and that the staff member knew his mother. The two spoke for a few moments about family before the bell rang. "I may have been asking the wrong questions," the teacher said to me as if there might be a 'special way' to talk. She seemed unsure about how the conversation went. She was only unsure because she had conversed so little with him in the past. She mentioned some early concerns his mother had about his education. Hopefully, I thought, simply sharing a short conversation would contribute to breaking down some inhibitions in the future and more conversations will occur.

\section{Transparency}

Running throughout each of these elements is the notion of transparency. Transparency, in this sense, is seeing what is present, but also seeing what is not. With an increased awareness of inclusion (and its flip side, exclusion), how values are put into practice in a school community become more visible. An essential element of whole-school re-culturing programmes, such as the Index for Inclusion, involve a period of self-review and reflection, of making the school community, its values and aspirations, more transparent. For the advocate and for the selfadvocate, this means being able to see what is not present and having a vision of what is desired. To develop relationships, it means being able to see the 'other' and bring them into a widening circle of friendships. During shared experiences it becomes clear who is, and who is not, participating. Creating and strengthening a sense of identity requires being able to see oneself and one's department or unit as an entity deserving of worth.

\section{EXPRESSING ELEMENTS OF INCLUSION THROUGH A SHARED EXPERIENCE}

The final three weeks of the school year provided an opportunity to put new expectations to use and develop the understanding behind them through a shared experience involving both staff and students. This experience contained key aspects of what have been identified as best practice for teacher professional learning and development (Timperley, Wilson, Barrar \& Fung, 2007). Staff, and students, were given the opportunity and time to explore ideas and integrate them into practice. Following the last exam, the school year for the senior (Year 11 to 13) students is over. Left on campus are the Year 9 and 10 students. Rather than continue with a normal schedule of class periods during these weeks, the principal and deputy principal put forward the idea of grouping the remaining students into their house groups and planning, with the students, high-interest learning activities centred around the key competencies found in the New Zealand Curriculum (Ministry of Education, 2007). The New Zealand curriculum considers key competencies the "capabilities people need in order to live, learn, work and contribute as active members of their community" (p. 11). These competencies are identified as managing self, relating to others, participating and contributing, thinking, and using language, symbols, and texts. The question posed by the principal and deputy principal was how to incorporate those competencies into a learning programme that was 'inclusive and responsive'.

Part of the importance of the three week project lies in expressing current values through a shared experience. Each house group encouraged student participation in planning the three weeks. All form teachers, including the unit teacher through to the teacher-aides, helped inform planning by asking students their interests. Student voice was then woven into what the house teachers collaboratively designed for the end-of-year project. Planning for the three 
weeks included all house teachers working together, and for the unit teacher and her colleagues it was the first time they collaborated in such a manner. The house in which they were members used the Index for Inclusion to inform their planning. Ideas were explored, passed around, altered. The participation of all staff in this project, including the unit teacher, was assumed as natural and expected. The participation of unit students was similarly taken as natural. Participation was not an issue as it was assumed that all house students would participate. Teachers from the learning support area began negotiating with the teacher-aides of the unit to prepare for some activities, and these teachers' expectation of the unit students were being clearly articulated and asserted.

The final three weeks of the year similarly provided an opportunity for these elements of inclusion to be experienced and reflected upon. Each Friday morning during this period was set aside as an extended staff briefing, facilitated by the principal and deputy principal to encourage reflection and forward thinking. "What can be taken forward to inform school planning?" staff were asked. "What are the implications for school reform that is inclusive and responsive?" The three week trial was, in essence, a shared experience in inclusion. Relationships were formed or strengthened, identities were created, and advocacy was practiced by both students and teachers, and integrated in the shared experience. The exercise of reflection, done daily by the students and collectively by the teachers at the staff briefings as well as extra staff meetings, provided a transparency that moved the school from a site based on a departmental structure to a more whole entity.

By re-grouping the students according to houses rather than form classes the teachers created five new and larger classes, involving colleagues and students who otherwise would not work closely together. Several teachers expressed a similar sentiment: "I enjoyed working with other staff, from different departments and skills, watching their teaching habits and ideals." The relationships formed were deepened as each staff member worked side-by-side with colleagues on a shared endeavour. As mentioned in the previous section, for many teachers it was the first time they had worked so closely with colleagues. These relationships also included the students, as they were able to work with many with whom they had previously had little contact. Students from the learning support area worked beside students from the whanau form class, just as students from 'extension' classes worked side-by-side with those from other form classes and year levels. One Year 9 student even expressed the desire to spend time and work with the students of the special needs unit when they did not take part in some activities, and this was negotiated into her schedule.

An important result of vertically combining year and ability groups was the strengthening of identity. Staff and students did not identify themselves to form classes during this time, but to houses, and the cohesion of each house increased as a result. "It's like it's no longer [learning support] and whanau, it is [the house]" one teacher commented. The identity built was also that of a more-integrated staff team and the collective student body. The extended staff briefings and group reflections contributed to that, as did the weekly group review sessions held by each house. As identity and relationships strengthened, staff and students advocated for each other, for breaking down streaming barriers, for more vertical groupings, and for wider participation. Again, the importance of a shared experience was also demonstrating to school leaders, teachers and students what they can achieve through working together, and the elements of inclusion being strengthened through that process.

\section{DISCUSSION}

In the subject school this has even resulted in a discussion of what is meant by the term 'mainstream'. The 'norm' is often a sort of unexamined and unquestioned 'ghost in the middle' (Bauman, 2011; Slee, 2011). By focusing on a minoritised or marginalised group the assumed 'mainstream' or 'normal' is not examined. However, as the nature of the school becomes more transparent, that space considered the 'norm' is increasingly examined and questions are asked, such as: "What is meant by 'mainstream'?" "Who, and who is not, in the 'mainstream'?" "Where are the borders of the 'mainstream' and should they be widened or even dissolved?" As the school becomes transparent there are fewer shadows in which exclusionary practice can exist. Looking at a conceptual map of the school I produced, the principal of my subject school immediately focused on those shadows, and his awareness thus became a type of spotlight. "How did I miss that last year? That was a real blind spot!" he said when looking at the positioning of specific departments. Practices previously ignored are increasingly questioned, and staff are creating ways to include previously marginalised students in the wider life of the school in meaningful ways, just as staff are also re-creating their concept of what they previously considered the 'mainstream'. The transparency encouraged in the process of developing a more inclusive school culture has enabled the elements of inclusion to be exercised, thereby strengthening the inclusive process. 
The Minister of Education would now, as part of the initiative Success for All: Every School, Every Child (Ministry of Education, 2012) like to see all schools in New Zealand as 'inclusive'. The aspiration of "a world class inclusive education system" (Ministry of Education, 1996, p. 5) dates back to Special Education 2000. The Inclusive Practices Tool (IPT) (NZCER, 2013) has been designed as a self-review mechanism for schools. The IPT comes as a result of the 2010 Education Review Office report and can be seen as part of a drive to make school practices accountable or measureable. In treating inclusion as a measureable goal or target to be attained, the Minister runs the risk of denying school communities the opportunity to develop their own culture of inclusion (McMaster, 2013). As the experiences of the subject school have indicated, shared experiences can provide opportunities to involve community members in developing relationships, empowering each participant, create identity as a whole and inclusive class or school, and visibly involve all members of the learning community. Whereas the three week experience at the subject school involved a great deal of planning and effort, any thoughtful shared experience can draw all the elements of inclusion together. The above research has illustrated how, through the process of co-creation, community members bring out the core elements of inclusion and, as a result, build and strengthen the culture of inclusion within their school.

\section{REFERENCES}

Ainscow, M. (2005). Developing inclusive education systems: What are the levers for change? Journal of Educational Change, 6, 109-124.

Allan, J. (2008). Rethinking inclusive education: The philosophers of difference in practice. Dordrecht: Springer.

Ballard, K. (2004). Children and disability: Special or included? Waikato Journal of Education, 10, 315326.

Bauman, Z. (2011). Culture in a liquid modern world. Cambridge: Polity.

Biklen, S. K., \& Bogdan, R. (2007). Qualitative research for education: An introduction to theories and methods. Boston, Mass: Pearson A \& B.

Booth, T., \& Ainscow, M. (2011). Index for inclusion: Developing learning and participation in schools. Bristol: Centre for Studies on Inclusive Education.

Carrington, S. (1999). Inclusion needs a different school culture. International Journal of Inclusive Education, 3(3), 257-268. doi: $10.1080 / 136031199285039$
Carrington, S., Deppeler, J., \& Moss, J. (2010). Cultivating teachers' beliefs, knowledge and skills for leading change in schools. Australian Journal of Teacher Education, 35(1), 1-13.

Cologon, K. (2013). Inclusion in education: Towards equality for students with disabilities Issues paper. Children and Families Research Centre, Institute of Early Childhood, Macquarie University.

Connor, D.J., Gabel, S.L., Gallagher, D.J., \& Morton, M. (2008). Disability studies and inclusive education: Implications for theory, research, and practice. International Journal of Inclusive Education, 12(5-6), 441-457.

Education Review Office. (2013). Including students with high needs: Primary schools (July 2013). Wellington, N. Z. : Education Review Office.

Joseph, K. A. (2007). Implementing the social model of disability: Theory and research. International Sociology Review of Books, 22(2), 247-250.

Kugelmass, J. W. (2006). The inclusive school: Sustaining equity and standards American Journal of Education, 112(4), 279-292.

Kvale, S. (2008). Doing interviews. Thousand Oaks: Sage Publications Ltd.

Madison, D. S. (2005). Critical ethnography: Method, ethics, and performance. Thousand Oaks: Sage.

McMaster, C. (2012). Ingredients for inclusion: Lessons from the literature. Kairaranga, 13(2), 11-22.

McMaster, C. (2013). The inclusive practices tools: Trying to take a short cut to inclusion? New Zealand Journal of Teacher's Work, 10(2). In press.

McMaster, C. (2014). An island outside the mainstream? The special needs unit during a period of inclusive change in an Aotearoa/New Zealand high school. Journal of the International Association of Special Education, 15(1). In press.

Ministry of Education (1996). Special Education 2000. Wellington, N.Z. : Ministry of Education.

Ministry of Education (2007). The New Zealand curriculum. Wellington: Learning Media.

Ministry of Education (2012). Success for all: Every school, every child. Retrieved from www. minedu.govt.nz/NZEducation/EducationPolicies/ SpecialEducation/OurWorkProgramme/ SuccessForAll.aspx

Mitchell, D. (2010). Education that fits: Review of international trends in the education of students with special educational needs. Final report. Christchurch: University of Canterbury. 
Neilson, W. (2005). Disability: Attitudes, history and discourses. In D. Fraser, R. Moltzen \& K. Ryba. (Eds.), Learners with Special Needs in Aotearoa New Zealand (3 ${ }^{\text {rd }}$ Edition), pp. 9-21. Melbourne: CENGAGE Learning.

NZCER (2013). Inclusive practices tools (IPT) development project. Retrieved March 28, 2013 from http://www.nzcer.org.nz/research/inclusivepractices-tools-ipt-development-project

O'Reilly, K. (2008). Key concepts in ethnography. London: Sage.

Oliver, M. (1990). The politics of disablement. London: Macmillan.

Oliver, M. (1996). Understanding disability: From theory to practice. New York: St. Martin's Press.

Oliver, M., \& Barnes, C. (2012). The new politics of disablement. New York: Palgrave Macmillan.

Slee, R. (2011). The irregular school: Exclusion, schooling, and inclusive education. New York: Routledge.

Timperley, H., Wilson, A., Barrar, H., \& Fung, I. (2007). Teacher professional learning and development: Best evidence synthesis iteration (BES). Wellington, N.Z. : Ministry of Education.

United Nations (1989). Convention on the rights of the child. New York: United Nations.

United Nations (2006). Convention on the rights of persons with disabilities. New York: United Nations.

Zollers, N. J., Ramanathan, A. K., \& Yu, M. (1999). The relationship between school culture and inclusion: How an inclusive culture supports inclusive education. International Journal of Qualitative Studies in Education, 12(2), 157-174. doi: 10.1080/095183999236231

\section{AUTHOR PROFILE}

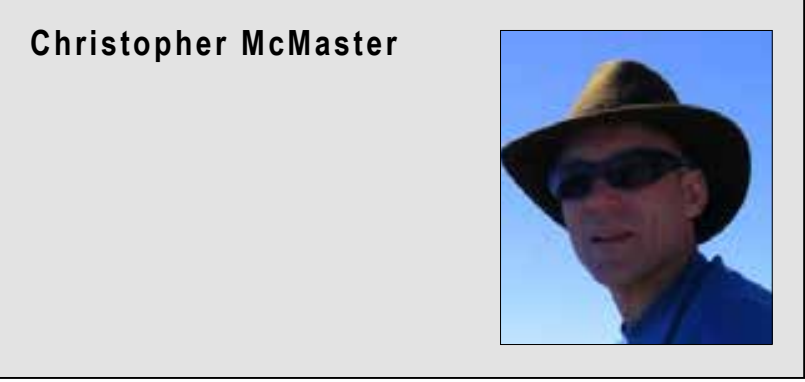

Christopher McMaster is a doctoral candidate at the University of Canterbury School of Educational Studies and Leadership. He has worked in education as a regular and special educator in the UK, US, and NZ. He began his Doctoral study in early 2012. His area of study is the re-culturing of school communities to reflect inclusive values and practices and he has spent the previous year embedded in a school community. He is using the Index for Inclusion in his research and has employed a critical ethnographic methodology. He is currently in the process of final thesis write up.

\section{Email:}

chris.mcmaster@pg.canterbury.ac.nz 